\title{
Interval between decision and delivery by caesarean section-are current standards achievable? Observational case series
}

\author{
Derek J Tuffnell, Kath Wilkinson, Nicola Beresford
}

Editorial by James
Papers p 1334
Maternity Unit,
Bradford NHS
Trust, Bradford
BD9 6RJ
Derek J Tuffnell
consultant
Kath Wilkinson
clinical governance
support officer
Nicola Beresford
senior house officer
Correspondence to:
DJ Tuffnell
derek.tuffnell@
bradfordhospitals.
nhs.uk

BMJ 2001;322:1330-3

\author{
Abstract \\ Objectives To audit interval from decision to delivery \\ in urgent caesarean section to determine whether the \\ current standard of 30 minutes is achievable \\ routinely; to determine whether delay leads to an \\ excess of admissions to special care. \\ Design Three audit cycles over four years followed by \\ a continuous audit over 32 months. \\ Setting Large district general hospital delivering 5500 \\ women each year. \\ Participants All women delivered by urgent \\ caesarean section for abnormal fetal heart rate \\ patterns, cord prolapse, failed instrumental delivery, \\ or suspected placental abruption.
}

Main outcome measures Proportion of women delivered within 30 and 40 minutes of decision. Admission rates to special care by length of interval between decision and delivery.

Results In the continuous audit 478 of 721 (66.3\%) women were delivered in 30 minutes and $637(88.3 \%)$ within 40 minutes; 29 (4.0\%) were undelivered at 50 minutes. If the woman was taken to theatre in 10 minutes, 409 of $500(81.8 \%)$ were delivered in 30 minutes and 495 (97\%) in 40 minutes. There was no significant difference in the proportion of babies born at 36 weeks or later who were admitted to special care, when analysed by interval from decision to delivery. $36 / 449(8 \%)$ babies with an interval from decision to delivery of less than 30 minutes were admitted to special care and 3/23 (13\%) with an interval of more than 50 minutes were admitted.

Conclusions The current recommendations for the interval between decision and delivery are not being achieved in routine practice. Failure to meet the recommendations does not seem to increase neonatal morbidity.

\section{Introduction}

When an urgent caesarean section is performed, it is widely advocated that the interval between the decision to operate and delivery of the baby should be less than 30 minutes. The recommendation states that a unit should be able to be ready to perform a caesarean section within 30 minutes, implying that the interval between decision and delivery may be a little longer. ${ }^{1-3}$ The clinical negligence scheme for trusts (CNST) has recommended that for units to achieve level 3 for a risk management accreditation they will need to audit their performance against this standard. ${ }^{4}$ The clinical justification for this arbitrary time standard does not come from trials or even from observational studies in humans but from a "pragmatic" approach. ${ }^{5}$ Preparing a woman for caesarean section is a complicated multidisciplinary task with inherent risks for mother and baby (box). Since 1993 our unit has audited the time from decision to perform a caesarean section to delivery of the baby, with a continuous audit since May 1997. This paper describes that process and discusses its implications.

\section{Participants, methods, and interventions}

The audit took place in a large district general hospital delivering about 5500 women a year. The rate of emergency caesarean section during the period of the audit was $9-12 \%$. The first audit was conducted from September to November 1993. There was no clear classification as to urgency, so this included all non-elective procedures. This led to a failure of

What has to be done between decision to deliver and delivery

Informed consent:

Consent form signed

Intravenous access

Blood samples to be taken

Blood forms to be filled in

Bloods to laboratory

Intravenous fluids running

Premedication to be got from drug cupboard

Premedication drawn up

Premedication injected

Anaesthetist informed

Operating department assistant informed

Consultant to be informed

Anaesthetist to arrive

Operating department assistant to arrive

Theatre to be set:

Scrub nurse to scrub

Packs to be opened

Sutures to be opened

Monitoring to be discontinued

Intravenous lines to be secured

Fetal scalp clip to be removed

Woman to be moved to theatre:

Woman to be moved on to theatre table

Spinal pack to be opened

Anaesthetist to scrub

Spinal drugs to be drawn up

Monitoring to be attached

Spinal anaesthesia

Wait for block to work:

Paediatrician to be present

Resuscitaire to be checked

Catheter

Shave

Surgeons to scrub

Skin preparation

Skin incision

Sheath incision

Peritoneum opened

Bladder reflected

Uterine incision

Deliver baby 
communication between professionals about urgency. Some delays were attributed to the time taken to prepare for spinal anaesthesia, and this was tackled by arranging for prepacked equipment for spinal anaesthesia to be available. After the first cycle it was agreed at a joint meeting with anaesthetists and obstetricians that urgent cases should meet the 30 minute standard and that "semi-urgent" cases should meet a 40 minute standard. Difficulty in agreeing on the categorisation of urgent caesarean section led to a delay before the second audit.

The second audit, in October to December 1995 , looked at each element of the process. One of the areas of delay was in moving the patient to theatre. There was organisational uncertainty about whose responsibility this was. The communication of urgency was felt to be poor. On at least three occasions the second theatre was not opened when appropriate. Recommendations were that a second theatre should be opened if there was any concern about the urgency of another caesarean section and that a team approach should be used to move patients to theatre within a target time of 10 minutes. The obstetrician was to tell the anaesthetist of the target time for delivery. The use of a 40 minute category was thought to be confusing so it was dropped.

In the third audit, from April to June 1996, delay in moving the women was highlighted as an issue. It was proposed that consent for the operation could be obtained once the patient had been moved, and it was also felt that increasing a woman's awareness that she might need a caesarean section could reduce the time needed to obtain consent.

From May 1997 we undertook a continuous audit of the time to delivery for caesarean section. The results were posted every three months on the delivery suite to provide feedback and they were discussed every six months at departmental audit meetings. As new registrars started in the unit they were informed of the ongoing audit, their responsibilities, and the need to aim for the 30 minute interval between decision and delivery. The consultant responsible for the delivery suite also initiated discussions about the need to move women swiftly to theatre and to communicate the degree of urgency.

We have used the continuous audit to analyse compliance with the standard in different clinical situations and to determine whether fetal outcome is affected by variance from the standard. All emergency caesarean sections were retrospectively assessed as to the need for delivery within 30 minutes. They were included if the delivery was because of an abnormal fetal heart rate trace, a cord prolapse, or failed instrumental vaginal delivery, or if there were other important concerns such as bleeding that suggested a diagnosis of placental abruption. Differences in outcome were assessed by rates of admission to the special care unit and analysed
Table 1 Times between decision to deliver and delivery, by year. Values are number (percentage) of cases

\begin{tabular}{lccc} 
& $\begin{array}{c}\text { May-Dec 1997 } \\
(\mathbf{n = 1 9 3 )}\end{array}$ & $\mathbf{1 9 9 8}(\mathbf{n = 2 4 1 )}$ & $\mathbf{1 9 9 9}(\mathbf{n = 2 8 7})$ \\
\hline Delivered in 30 minutes & $120(62)$ & $166(68)$ & $192(67)$ \\
\hline Delivered in 40 minutes & $163(84.5)$ & $213(88)$ & $261(91)^{\star}$ \\
\hline Delivered in $>50$ minutes & $12(6.2)$ & $7(3.2)$ & $10(3.5)$ \\
\hline Theatre in 10 minutes: & & \\
\hline Delivered in 30 minutes & $98 / 120(82)$ & $137 / 163(84)$ & $174 / 217(80)$ \\
\hline Delivered in 40 minutes & $114 / 120(95)$ & $157 / 163(96)$ & $214 / 217(99)$ \\
\hline Theatre in $>10$ minutes: & & & \\
\hline Delivered in 30 minutes & $22 / 73(30)^{\star \star}$ & $29 / 78(37)^{\star \star}$ & $18 / 70(25)^{\star *}$ \\
\hline Delivered in 40 minutes & $49 / 73(67)^{\star \star}$ & $56 / 78(71)^{\star \star}$ & $47 / 70(67)^{\star *}$ \\
\hline
\end{tabular}

${ }^{\star} P<0.05$ compared with 1997 .

${ }^{* *} \mathrm{P}<0.001$ compared with group to theatre in 10 minutes.

using the $\chi^{2}$ test. The reasons for considerable delays (>50 minutes) were analysed separately.

\section{Results}

During the first cycle 188 cases of emergency section occurred, of which $77(41 \%)$ had a time of under 30 minutes between decision and delivery.

In the second cycle 55 of $107(51 \%)$ cases were considered to need delivery within 30 minutes; 38 of $55(69 \%)$ cases achieved this. A total of $23(22 \%)$ cases were considered to need delivery within 40 minutes; 14 (61\%) achieved this.

In the third cycle 58 of $135(43 \%)$ cases needed delivery within 30 minutes; $32(60 \%)$ cases were delivered in 30 minutes and $50(86 \%)$ in 40 minutes. The audit showed that if women were in theatre within 10 minutes then $70 \%$ would be delivered within 30 minutes.

During the fourth cycle 721 of 1344 (54\%) non-elective caesarean sections needed urgent delivery. Of these, $478(66 \%)$ were delivered within $30 \mathrm{~min}$ utes and $637(88 \%)$ within 40 minutes; 29 (4\%) were undelivered at 50 minutes. A total of $500(69 \%)$ women got to theatre within 10 minutes; $409(82 \%)$ were delivered in 30 minutes and $485(97 \%)$ in 40 minutes. If it took 10 minutes to get to theatre, only $69 / 221(31 \%)$ of women were delivered in 30 minutes $(\mathrm{P}<0.001)$ and $152 / 221(69 \%)$ in 40 minutes $(\mathrm{P}<0.001)$. Significantly more women were delivered within 40 minutes in 1999 than in $1997(261 / 287 v 163 / 193 ; \mathrm{P}<0.05$, table 1$)$. No other differences between years were significant.

Fewer babies were admitted to special care when the interval between decision and delivery was shorter, but not when prematurity was excluded as a reason for admission to special care (tables 2 and 3). Three babies born at 28, 32, and 32 weeks, whose intervals between decision and delivery were 41, 30, and 26 minutes, later died. All babies were in reasonable condition at birth and died when several days old. Six babies born at term needed ventilation. Five had only short term ventila-

Table 2 Admission to special care of babies delivered by emergency caesarean section. Values are numbers (percentages) of babies

\begin{tabular}{|c|c|c|c|c|c|}
\hline \multirow[b]{2}{*}{ Gestation } & \multicolumn{4}{|c|}{ Time from decision to delivery } & \multirow[b]{2}{*}{ Total } \\
\hline & $<30$ minutes & 31-40 minutes & 41-50 minutes & $>\mathbf{5 0}$ minutes & \\
\hline Total & $65 / 478^{*}(14)$ & $23 / 159^{* *}(15)$ & $9 / 55(16)$ & $9 / 29(31)$ & $106 / 721(15)$ \\
\hline 36 weeks and over & $36 / 449(8)$ & $8 / 144(5.5)$ & $1 / 47(2)$ & $3 / 23(13)$ & $48 / 663(7)$ \\
\hline
\end{tabular}

${ }^{\star} \mathrm{P}<0.01$ compared with $>50$ minutes.

${ }^{*} \mathrm{P}<0.05$ compared with $>50$ minutes. 
Table 3 Reason for admission to neonatal special care after delivery by emergency caesarean section

\begin{tabular}{lcccccc} 
& \multicolumn{3}{c}{ Interval between decision and delivery } & All \\
\cline { 2 - 6 } Reason for admission & $\mathbf{< 3 0}$ minutes & $\mathbf{3 1 - 4 0}$ minutes & $\mathbf{4 1 - 5 0}$ minutes & $\mathbf{5 0}$ minutes & $(\mathbf{n = 1 0 8 )}$ \\
\hline Prematurity & 29 & 15 & 8 & 6 & 58 \\
\hline Ventilation & 6 & 0 & 0 & 1 & 7 \\
\hline Observation after resuscitation & 10 & 3 & 1 & 0 & 14 \\
\hline Weight $<2.1 \mathrm{~kg}$ & 9 & 3 & 0 & 2 & 14 \\
\hline Anomaly & 6 & 0 & 0 & 0 & 6 \\
\hline Hypoglycaemia (diabetic mother) & 2 & 2 & 0 & 0 & 4 \\
\hline Other & 3 & 0 & 0 & 0 & 3 \\
\hline
\end{tabular}

Table 4 Reasons for delay of more than 50 minutes between decision to deliver and delivery by caesarean section. Values are numbers of deliveries

\begin{tabular}{lcccr} 
Reason for delay & $\mathbf{1 9 9 7}$ & $\mathbf{1 9 9 8}$ & $\mathbf{1 9 9 9}$ & Total \\
\hline Multiple attempts at spinal anaesthesia & 2 & 4 & 6 & 12 \\
\hline Awaiting epidural top-up & 2 & 1 & 0 & 3 \\
\hline Delay getting consent* & 2 & 0 & 2 & 4 \\
\hline Delay moving to theatre & 2 & 2 & 1 & 5 \\
\hline Delay getting staff because of another caesarean section & 2 & 0 & 1 & 3 \\
\hline Awaiting results of blood tests & 1 & 0 & 0 & 1 \\
\hline Not clear & 1 & 0 & 0 & 1 \\
\hline
\end{tabular}

*Problem was long explanation rather than reluctance to agree.

tion and had no long term adverse events. The interval between decision and delivery in these cases was 18,25 , 30,30 , and 77 minutes. One baby had signs of hypoxic ischaemic encephalopathy with fits. The mother had had an abruption and the interval between decision and delivery was 20 minutes. The interval between admission and delivery was less than 50 minutes.

Delays of more than 50 minutes stemmed largely from problems in providing anaesthesia or delays in getting the woman to theatre (table 4).

\section{Discussion}

A caesarean section is a complex multidisciplinary procedure. The Royal College of Obstetricians and Gynaecologists, the Obstetric Anaesthetists Association, the Royal College of Midwives, the Clinical Negligence Scheme for Trusts, and controls assurance standards have recommended that caesarean section should be ready to be performed within 30 minutes. ${ }^{1-4}$ This learned body of opinion places a great responsibility on the shoulders of clinicians faced with delivering babies in an emergency. It also provides a large body of evidence to be quoted as suggesting negligent care should a baby be born in suboptimal condition when there has been a delay of more than 30 minutes. Our audit questions whether the standard as established is "reasonable."

Many tasks, some of which are quite complex (see box, p 1330), are needed to perform an emergency caesarean section. The procedure needs at least seven professionals - an anaesthetist and a skilled assistant, an obstetrician and an assistant, a theatre nurse or midwife to assist with the operation, a midwife, and a paediatrician to take the baby. The staff have to be assembled before the necessary complex tasks can be undertaken.

Anaesthesia

One of the major successes in maternal outcome has been that anaesthesia now rarely causes death in women having caesarean section. ${ }^{6}$ Anaesthetists have a primary responsibility to the mother and reasonably guard their right to ensure that the procedure they use is safest for the mother, yet they are expected to do complex tasks under pressure of time. This emphasis on maternal safety may conflict with concerns about the baby. The increased safety of regional anaesthesia has been shown. ${ }^{78}$ Regional anaesthesia is often as quick to administer as general anaesthesia but no randomised controlled trial has looked at the time taken to be ready to start surgery with each method. The move to increased use of regional anaesthesia gives concern that training in obstetric general anaesthesia is threatened. $^{9-12}$ The decision to convert to general anaesthesia when there is difficulty with spinal anaesthesia is one that trainees in particular may be increasingly reluctant to make. The rate of failed intubation is higher in the cases now managed with general anaesthesia. $^{9}$

\section{Audits of timing}

The audit shows that even with an emphasis on the need to deliver babies promptly in situations where there is concern about fetal wellbeing or maternal wellbeing, the standard as laid down nationally cannot be met in a considerable minority of cases. The question this raises is whether a "reasonable" doctor will fail in this considerable minority. When medicolegal experts review cases retrospectively, knowing the outcome for the baby, then the interval between decision and delivery is certain to be examined. If the arbitrary national standard is used then it may well be that a considerable number of cases will be judged to have received "unreasonable" care. It is probably more appropriate to consider what proportion of cases will be delivered within a particular time from the decision to deliver in a real, day to day situation. Audit of the time between decision and delivery in a teaching unit has produced results similar or worse to ours. ${ }^{13}$

The first three cycles of our audit showed the difficulties of producing clear definitions of urgent cases. When time is less important, we found that it is more pragmatic to detail cases as urgent (requiring delivery as soon as possible, aiming for 30 minutes) or non-urgent. Lucas et al have considered the classification of urgency. ${ }^{14}$ Our cases would be classified as urgent or emergency by Lucas et al's criteria. They do not suggest an appropriate interval between decision and delivery. In their paper they tested a classification based on time, and it performed poorly.

In our unit the early audits did show the key areas of ensuring all appropriate staff are available, as reinforced recently by the Confidential Enquiry into Stillbirths and Deaths in Infancy. ${ }^{5}$ The movement of the woman to the area where the caesarean is to be performed was seen as critical. If more than 10 minutes elapses then it is considerably less likely that the baby will be delivered in 30 or 40 minutes. This rapid transfer can be distressing for women. They can be concerned that control of the situation is being taken from them; it may add to their anxieties about their baby; and it may have implications for the future relationship between mother and baby. Midwives are often anxious about moving women before the women have an understanding of what is happening. This is even more the case when there are communication problems because the women do not have English as a first language. 
The importance of recording the time of the events around delivery and auditing them is encouraged by the inquiry. ${ }^{5}$ This report also emphasises the need for team working. The inquiry's recommendations include the advice that only one attempt at spinal anaesthesia is appropriate when general anaesthesia poses no great risk. It means that obstetricians and midwives must be willing to communicate urgency to anaesthetists and remind them of the passage of time. It is notable that in our audit 12 of 29 delays of greater than 50 minutes were due to multiple attempts at spinal anaesthesia. This provides some evidence of reluctance to resort to general anaesthesia.

\section{Fetal wellbeing}

The main reason for urgent delivery is the presumption that it is important for fetal wellbeing. Although, in our series, there was a difference in the rate of admission to special care when times from decision to delivery were compared, this difference did not hold when premature cases were excluded. The lack of difference in rate of admission for term infants could be for several reasons. It could be because this audit did not include enough babies or did not contain enough genuinely compromised babies. Only one baby would have fulfilled the criteria of the international consensus statement relating cerebral palsy to peripartum events. ${ }^{15}$ This is the classic dilemma for obstetricians. If intervention leads to a good outcome it is seen as unnecessary; if it leads to a bad outcome it is seen as too slow or too late.

The numbers in this audit indicate that delay is an unusual cause of neonatal problems. It could be that the time taken to deliver makes no difference. This is scientifically unlikely, as a compromised baby is going to deteriorate if left in an unfavourable environment. However, it may be that for the most part a baby can recover from any additional compromise caused by the delay. Delays of up to 50 minutes seem to be an unlikely cause of problems for an infant. It may also be that the obstetricians in these cases somehow knew and correctly selected the most compromised babies for the fastest delivery. Analysis of this is difficult.

Cases delivered because of fetal bradycardia (49/66 in $30 \mathrm{~min}, 61$ in $40 \mathrm{~min}$ ) or with an abnormal cord $\mathrm{pH}$ (148/196 in $30 \mathrm{~min}, 181$ in $40 \mathrm{~min}$ ) were delivered faster than those with an abnormal cardiotocograph in whom determining the $\mathrm{pH}$ was not possible because it was too early in labour $(85 / 186$ in $30 \mathrm{~min}, 142$ in 40 min; $\mathrm{P}<0.001)$. All 15 cases of cord prolapse were delivered within 30 minutes, as were 60 of 63 cases of failed instrumental delivery. This suggests some element of selection by attending clinicians. If we tried to retrospectively separate our cases by the Lucas classification of urgency $^{14}$ then cases with cord prolapse, fetal bradycardia, and failed instrumental delivery would be classed as "emergency cases." We delivered 124/144 (86\%) in 30 minutes and 139 (97\%) in 40 minutes. If cases with a low $\mathrm{pH}$ were also included this would be $272 / 340(80 \%)$ in 30 minutes and 320 (94\%) in 40 minutes.

Throughout the time of our audits we have reduced delays but this has not been at a statistically significant level. In practical terms, long delays are much less common. We still deliver only two out of three babies in the recommended time and nine out of 10 within 40

\section{What is already known on this topic}

Many national bodies recommend that when a decision is made to deliver a baby by caesarean section because of fetal distress, the baby should be delivered within 30 minutes

There are no clear classifications of what is urgent nor any evidence that this standard is achievable in routine practice

\section{What this study adds}

Delivery within 30 minutes is achievable in only two out of three cases; $88 \%$ will be delivered in 40 minutes; up to $4 \%$ of women will remain undelivered at 50 minutes

Delay in delivery made no difference to the rate of admission to special care for babies over 36 weeks' gestation

minutes. These figures should be borne in mind when criticisms are made in cases where "excess delay" leads to a compromised infant.

Contributors: DJT conceived the idea, analysed the data, wrote the paper, and is the guarantor. KW collected the maternal data, and NB collected the neonatal data. All were involved in the interpretation of data and the drafting and final approval of the paper.

Funding: No external funding.

Competing interests: DJT was an author of the Confidential Enquiry into Stillbirths and Deaths in Infancy focus group on obstetric anaesthesia. He acts as an expert witness in medicolegal cases for claimants and defendants.

1 Association of Anaesthetists of Great Britain and Ireland, Obstetric Anaesthetists Association. Guidelines for obstetric anaesthesia services. London: Association of Anaesthetists of Great Britain and Ireland, Obstetric Anaesthetists Association, 1998.

2 Royal College of Obstetrics and Gynaecology. Anaesthesia cover should be audited along with response times involving anaesthesia. In: Organisational standards for maternity services. London: Royal College of Obstetrics tional standards for maternity .

3 Royal College of Obstetrics and Gynaecology and Royal College of Midwives. Developing standards. In: Towards safer childbirth. London: Royal College of Obstetrics and Gynaecology and Royal College of Midwives, 1999:17-8.

4 Clinical Negligence Scheme for Trusts. Clinical risk management standards. London, 1999. (Criterion 12;3;1.)

5 Focus Group. Obstetric anaesthesia delays and complications. In: Confidential enquiry into stillbirths and deaths in infancy. 7 th annual report. Lonfidential enquiry into stillbirths and deaths in infancy. 7th annual report.

6 Deaths associated with anaesthesia. In: Why mothers die. Confidential enquiry into maternal deaths in the United Kingdom 1994-1996. London: Stationery Office, 1997:91-102.

7 Hawkins JL, Koonin LM, Palmer SK, Gibbs CP. Anaesthesia related deaths during obstetric delivery in the United States, 1979-1990. Anesthesiology 1997:86:277-84.

8 Chadwick HS, Posner K, Caplan RA, Ward RJ, Cheney FW. A comparison of obstetric and nonobstetric anesthesia malpractice claims. Anesthesiology 1991;74:242-9.

9 Hawthorne L, Wilson R, Lyons G, Dresner M. Failed intubation revisited: 17-yr experience in a teaching maternity unit. BrJAnaesth 1996;76:680-4.

10 Brown GW, Russell IF. A survey of anaesthesia for caesarean section. Int J Obstet Anaesth 1995;4:214-8.

11 Madej TH, Jackson IJB, Wheatley RG, Wilson J. Assessing introduction of spinal anaesthesia for obstetric procedures. Qual Health Care 1993;2:31-4.

12 Johnson RV, Lyons GR, Wilson RC, Robinson AP. Training in obstetric general anaesthesia: a vanishing art? Anaesthesia 2000;55:179-83.

13 Dwyer JP. Decision to delivery time in emergency caesarean section. Abstract Book, Fourth International Scientific Meeting of the Roya College of Obstetrics and Gynaecology. Cape Town 4-6 October 1999:13.

14 Lucas DN, Yentis SM, Kinsella SM, Holdcroft A, May AE, Wee M, et al. Urgency for caesarean section: a new classification. $I R$ Soc Med 2000;93:346-50

15 MacLennan A. A template for defining a causal relationship between acute intrapartum events and cerebral palsy: international consensus statement. BMJ 1999;319:1054-9.

(Accepted 2 February 2001) 